\title{
Structural Evaluation of 5,5-Bis(naphth-2-yl)-2,2-bithiophene in Organic Field-Effect Transistors with n-Octadecyltrichlorosilane Coated SiO2 Gate Dielectric
}

Lauritzen, Andreas E. ; Torkkeli, Mika; Bikondoa, Oier; Linnet, Jes; Tavares, Luciana; Kjelstrup-Hansen, Jakob; Knaapila, Matti

\section{Published in:}

Langmuir

Link to article, DOI:

10.1021/acs.langmuir.8b00972

Publication date:

2018

Document Version

Peer reviewed version

Link back to DTU Orbit

Citation (APA):

Lauritzen, A. E., Torkkeli, M., Bikondoa, O., Linnet, J., Tavares, L., Kjelstrup-Hansen, J., \& Knaapila, M. (2018). Structural Evaluation of 5,5-Bis(naphth-2-yl)-2,2-bithiophene in Organic Field-Effect Transistors with n-

Octadecyltrichlorosilane Coated SiO Gate Dielectric. Langmuir, 34, 6727-6736.

https://doi.org/10.1021/acs.langmuir.8b00972

\section{General rights}

Copyright and moral rights for the publications made accessible in the public portal are retained by the authors and/or other copyright owners and it is a condition of accessing publications that users recognise and abide by the legal requirements associated with these rights.

- Users may download and print one copy of any publication from the public portal for the purpose of private study or research.

- You may not further distribute the material or use it for any profit-making activity or commercial gain

- You may freely distribute the URL identifying the publication in the public portal 
Subscriber access provided by DTU Library

\section{Interfaces: Adsorption, Reactions, Films, Forces, Measurement Techniques, Charge}

\section{Transfer, Electrochemistry, Electrocatalysis, Energy Production and Storage}

Structural evaluation of 5,5'-bis(naphth-2-yl)-2,2'-bithiophene in organic fieldeffect transistors with n-octadecyltrichlorosilane coated SiO2 gate dielectric

Andreas Ejdrup Lauritzen, Mika Torkkeli, Oier Bikondoa, Jes Linnet,

Luciana Tavares, Jakob Kjelstrup-Hansen, and Matti Knaapila

Langmuir, Just Accepted Manuscript • DOI: 10.1021/acs.langmuir.8b00972 • Publication Date (Web): 11 May 2018

Downloaded from http://pubs.acs.org on May 14, 2018

\section{Just Accepted}

"Just Accepted" manuscripts have been peer-reviewed and accepted for publication. They are posted online prior to technical editing, formatting for publication and author proofing. The American Chemical Society provides "Just Accepted" as a service to the research community to expedite the dissemination of scientific material as soon as possible after acceptance. "Just Accepted" manuscripts appear in full in PDF format accompanied by an HTML abstract. "Just Accepted" manuscripts have been fully peer reviewed, but should not be considered the official version of record. They are citable by the Digital Object Identifier (DOI®). "Just Accepted" is an optional service offered to authors. Therefore, the "Just Accepted" Web site may not include all articles that will be published in the journal. After a manuscript is technically edited and formatted, it will be removed from the "Just Accepted" Web site and published as an ASAP article. Note that technical editing may introduce minor changes to the manuscript text and/or graphics which could affect content, and all legal disclaimers and ethical guidelines that apply to the journal pertain. ACS cannot be held responsible for errors or consequences arising from the use of information contained in these "Just Accepted" manuscripts. 


\title{
Structural evaluation of 5,5'-bis(naphth-2-yl)-2,2'-
}

\section{bithiophene in organic field-effect transistors with $\mathrm{n}$ - octadecyltrichlorosilane coated $\mathrm{SiO}_{2}$ gate dielectric}

\author{
Andreas E. Lauritzen, ${ }^{1,2, *}$ Mika Torkkeli, ${ }^{1}$ Oier Bikondoa, ${ }^{3,4}$ Jes Linnet,, 5 Luciana Tavares, ${ }^{6}$ Jakob \\ Kjelstrup-Hansen, ${ }^{6, *}$ and Matti Knaapila ${ }^{1, *}$ \\ ${ }^{1}$ Department of Physics, Technical University of Denmark, 2800 Kgs. Lyngby, Denmark, ${ }^{2}$ \\ Department of Physics, University of Oxford, OX1 3PU Oxford, UK, ${ }^{3}$ XMaS, The UK-CRG \\ Beamline, European Synchrotron Radiation Facility, 38043 Grenoble Cedex 09, France, ${ }^{4}$ Department \\ of Physics, University of Warwick, CV4 7AL Coventry, UK, ${ }^{5}$ Center for Nano Optics, Mads Clausen \\ Institute, University of Southern Denmark, 5230 Odense M, Denmark, ${ }^{6}$ NanoSYD, Mads Clausen \\ Institute, University of Southern Denmark, 6400 Sønderborg, Denmark
}




\begin{abstract}
We report on the structure and morphology of 5,5'-bis(naphth-2-yl)- 2,2'-bithiophene (NaT2) films in bottom-contact organic field-effect transistors (OFETs) with octadecyltrichlorosilane (OTS) coated $\mathrm{SiO}_{2}$ gate dielectric, characterized by atomic force microscopy (AFM), grazing-incidence X-ray diffraction (GIXRD) and electrical transport measurements. Three types of devices were investigated with the NaT2 thin-film deposited either on (1) pristine $\mathrm{SiO}_{2}$ (corresponding to higher surface energy, $47 \mathrm{~mJ} / \mathrm{m}^{2}$ ) or on OTS deposited on $\mathrm{SiO}_{2}$ under (2) anhydrous or (3) humid conditions (corresponding to lower surface energies, $20-25 \mathrm{~mJ} / \mathrm{m}^{2}$ ). NaT2 films grown on pristine $\mathrm{SiO}_{2}$ form nearly featureless 3-dimensional islands. NaT2 films grown on $\mathrm{OTS} / \mathrm{SiO}_{2}$ deposited under anhydrous conditions form staggered pyramid islands where the interlayer spacing corresponds to the size of the NaT2 unit cell. At the same time, the grain size measured by AFM increases from hundreds of nanometers to micrometers and the crystal size measured by GIXRD from $30 \mathrm{~nm}$ to more than $100 \mathrm{~nm}$. NaT2 on $\mathrm{OTS} / \mathrm{SiO}_{2}$ deposited under humid conditions also promotes staggered pyramids but with smaller crystals $30-80 \mathrm{~nm}$. The NaT2 unit cell parameters in OFETs differ $1-2 \%$ from those in bulk. Carrier mobilities tends to be higher for NaT2 layers on $\mathrm{SiO}_{2}\left(2-3 \cdot 10^{-4} \mathrm{~cm}^{2} / \mathrm{Vs}\right)$ compared to NaT2 on OTS $\left(2 \cdot 10^{-5}-1 \cdot 10^{-4} \mathrm{~cm}^{2} / \mathrm{Vs}\right)$. An applied voltage does not influence the unit cell parameters when probed by GIXRD in operando.
\end{abstract}

Keywords: conjugated oligomers; oligothiophenes; OFETs; GIWAXS; GIXRD in operando; directional crystallite size 


\section{INTRODUCTION}

$\pi$-Conjugated oligomers are often used in organic field-effect transistors (OFETs) and related devices where the interface structure and film morphology including crystal size are closely related to the carrier mobilities. ${ }^{1-3}$ Characteristic for these thin-film devices are various crystal growth and interface phenomena including substrate-induced phases (SIPs) driven by the film and device environment and confinement. ${ }^{4,5}$ Important factors for the vacuum deposition are the rate of nucleation, the growth mode and the grain size and connectivity.-9 In this process, the molecules adsorb and desorb in a dynamic manner. The more tightly the adsorbed molecules are bound to the surface, the less time they have to desorb and the more time they have to diffuse and nucleate into stable clusters with other molecules. Some molecules manifest 2-dimensional growth mode (layer-by-layer or Frank-van der Merwe), whereas others manifest 3-dimensional growth modes (island formation or Volmer-Weber) or their combination (a monolayer-plus islands or Stranski-Krastanov). All this depends on the surface morphology and surface and interface energies.

One commonly employed strategy to modify the interface structure in OFETs is to incorporate a selfassembled monolayer (SAM) atop the OFET gate dielectric. ${ }^{10-13}$ The SAM surface smoothens the nontreated surface and typically lowers its surface energy with manifold effects on the morphology and structure of the active layer. While the bulk structure can be significantly influenced by SAMs, every molecule-surface combination has its own specific energetic interactions and must be considered unique.

Bao and co-workers ${ }^{14,15}$ compared pentacene deposited on either vapor deposited or spin-coated octadecylthrichlorosilane (OTS) layers on $\mathrm{SiO}_{2} / \mathrm{Si}$ in OFETs and studied these configurations by AFM and grazing-incidence X-ray diffraction (GIXRD). They showed how the spin-coating promotes 
crystallinity of OTS and 2D rather than $3 \mathrm{D}$ or island growth of pentacene. In another example, the same authors used various fluorene-bithiophene-fluorenes as active layers and reported two different unit cells, rectangular and monoclinic, depending on the film thickness. ${ }^{16}$

Elsewhere, Walter et al. ${ }^{17}$ prepared similar OFETs with a benzothienodithiophene derivative and deposited an OTS layer either under anhydrous or humid conditions. These authors found that both the crystal size of the organic semiconductor thin-film and the corresponding charge carrier mobility increase with higher relative humidity during OTS deposition.

In another consideration, Yang et al. ${ }^{18}$ studied pentacene OFETs and coated the gate dielectric by chemically different poly(imide-siloxane)s with a range of surface energies. The authors found that the pentacene growth mode changes from Stranski-Krastanov growth mode to Volmer-Weber mode with lowering surface energy. Counterintuitively, the authors observed higher carrier mobilities for the latter mode with smaller grains. They interpreted this in terms of better interconnections and improved intergrain contacts.

The possibilities to synthesize $\pi$-conjugated oligomers have become exceedingly advanced. ${ }^{19,20}$ One line of research has been on aryl end-capped oligothiophenes where substitutions are used to avoid polymerization, oxidation and degradation and to promote intermolecular packing. The end-caps include fluorene, ${ }^{21}$ naphthyl and thionaphthyl, ${ }^{22} \mathrm{~N}$-containing aryls, ${ }^{23}$ or styrene or 1-pentyl -4vinylbenzene $^{24}$ variants to name a few. Common to all these materials are good thermal and chemical stability and the carrier mobilities falling within the range of $10^{-3}-10^{-2} \mathrm{~cm}^{2} / \mathrm{Vs}$. These materials tend to form polycrystalline films where the characteristically rigid molecules organize along the surface normal in an end-to-end manner. 
Kjelstrup-Hansen and co-workers have recently placed attention on 5,5'bis(naphth-2-yl)-2.2bithiophene (NaT2) - a naphthyl end-capped oligothiophene synthesized first by Tian et al. ${ }^{22}$ This material is suitable for thin-film devices and maintains its structure in OFETs over long (10 hrs) periods. ${ }^{25}$ It also shows peculiar crystal growth effects forming nanometers thick but micron long fibrous structures on mica. ${ }^{26}$ The nanofibers can be employed further in low voltage phototransistors, ${ }^{27}$ where the molecular alignment in the fibrous structures results in strong optical absorption. ${ }^{28}$ This motivated us to find further ways to control NaT2 structure and morphology.

In this paper, we investigate structure and morphology of NaT2 in bottom-contact bottom-gate OFETs with and without an OTS layer prepared under anhydrous or humid conditions. We find that OTS promotes staggered 3-dimensional structures and increases lateral crystal size from $30 \mathrm{~nm}$ to 100 nm. At the same time we observe a slight lowering of the hole mobility. Unlike Walter et al. ${ }^{17}$, we observe that the OTS layer deposited under anhydrous conditions lead to largest effect on the apparent grain size and measured crystal size. We also monitor NaT2 structure in operando and found it stable with OTS layer. These results provide new structural insight on interesting NaT2 materials in an OFET environment. 


\section{EXPERIMENTAL SECTION}

Materials. Scheme 1 shows the chemical structure of NaT2. The synthesis of NaT2 followed a Stille cross-coupling approach as described in Ref. ${ }^{27}$ OTS (>90\%), hexane (95\% purity) and toluene $(99.8 \%$ purity) were purchased from Sigma-Aldrich.

Scheme 1. Chemical structure of NaT2.

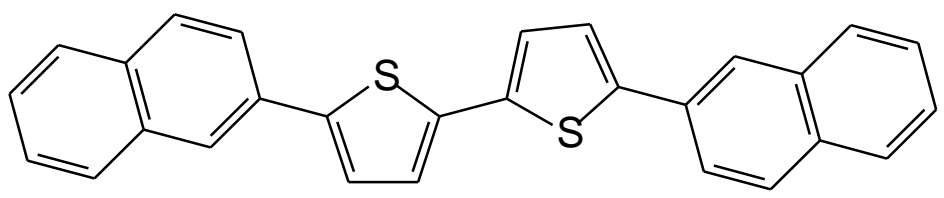

Substrate fabrication. Figure 1(a) illustrates the design of employed OFETs. The OFET substrates were fabricated as reported by us. ${ }^{25}$ The substrates consisted of n-doped Si that served as both carrier substrate as well as back gate electrode covered by a $200 \mathrm{~nm}$ thick thermally grown $\mathrm{SiO}_{2}$ dielectric layer. Interdigitated source and drain electrodes were prepared by electron beam evaporation of $\mathrm{Ti} / \mathrm{Au}$ $(3 \mathrm{~nm} / 30 \mathrm{~nm})$ and patterned by photolithography and lift-off processes on top of the $\mathrm{SiO}_{2}$. Fabricated substrates were cleaned in acetone, isopropanol and lastly deionized water under sonication for $3 \mathrm{~min}$ and dried in a nitrogen gas.

The source and drain electrodes were separated by a $500 \mu \mathrm{m}$ gap and the finger width was $20 \mu \mathrm{m}$. The transistor channel had a width-to-length ratio of 269 . The area covered by the interdigitated electrode pattern was $10 \mathrm{~mm} \times 10 \mathrm{~mm}$. In this design, only $4 \%$ of the active layer was on top of the gold electrodes and most the film was consequently deposited directly on the gate dielectric. The design was made to be compatible with ZIF (zero insertion force) sockets, which allowed easy and consistent sample mounting while performing GIXRD measurements in operando (see below). 
(a)

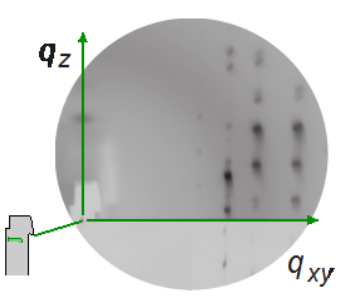

beam stop

(b)

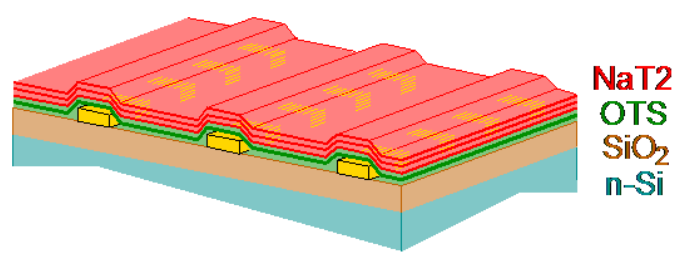

Figure 1. (a) Illustration of employed OFET design allowing GIXRD studies in operando and (b) the layer profile of the interdigitated electrode area. Not drawn to scale.

Table 1. Notation of OFET configurations based on the film thickness and substrate treatment. ${ }^{a}$

\begin{tabular}{cccc}
\hline $\begin{array}{c}\text { Thickness of } \\
\text { NaT2 layer }(\mathrm{nm})\end{array}$ & $\begin{array}{c}\text { No } \\
\text { OTS }\end{array}$ & $\begin{array}{c}\text { OTS - anhydrous } \\
\text { deposition }\end{array}$ & $\begin{array}{c}\text { OTS - humid } \\
\text { deposition }\end{array}$ \\
\hline 7.9 & N8 & A8 & H8 \\
10.9 & N11 & A11 & H11 \\
25.1 & N25 & A25 & H25 \\
\hline \hline
\end{tabular}

${ }^{a}$ The film thickness is determined by a QCM thickness monitor.

Organic film deposition. Figure 1(b) illustrates the deposited layers in the studied OFETs. Table 1 lists the different sample configurations referred to throughout this paper. Three types of devices were investigated. NaT2 film deposited on (1) pristine $\mathrm{SiO}_{2}$, (2) OTS deposited on $\mathrm{SiO}_{2}$ under anhydrous conditions and (3) OTS deposited on $\mathrm{SiO}_{2}$ under humid conditions. The samples are denoted as "N", "A" and "H" referring to "none", "anhydrous" and "humid", respectively. The subsequent number refers to the nominal thickness of NaT2 layer. This would be the physical film thickness if the all the material was evenly distributed on the substrate. The OTS monolayers were deposited following methods of Walter et al. ${ }^{17}$ 
For anhydrous OTS depositions, the OTS-toluene solution was mixed in a nitrogen-purged glove box and the OFET substrates were immersed in this solution in capped beakers for 15 hours. After removing the substrates from the solution, they were cleaned in acetone, isopropanol and lastly deionized water under sonication for $3 \mathrm{~min}$ and dried in a nitrogen stream. For humid OTS deposition, the OTS-hexane solution was mixed in a fume hood with $48 \%$ relative humidity. The beaker with this solution was left to stabilize for an hour. This ensured equilibrium between the humid air and the solution. The substrates were subsequently immersed in this solution for an hour. After removal, they were cleaned in the same way as the substrates prepared in anhydrous conditions. Finally, nominally 8 $\mathrm{nm}, 11 \mathrm{~nm}$, or $25 \mathrm{~nm}$ thick NaT2 layers were deposited on all three types of substrates by vacuum sublimation on top of the transistor substrates. The deposition pressure was $10^{-8}$ mbar and the deposition rate $\approx 0.1 \AA / s$. The film thickness was determined by a quartz crystal microbalance (QCM) thickness monitor. All substrates and OFETs were stored under vacuum after preparation and between characterizations.

Surface energy characterization. The surface energies of OFET substrates were estimated by measuring the contact angles of three test liquids, water, diiodomethane and ethylene glycol. The evaluation considers the geometric mean of the dispersive and polar parts of the surface tensions of liquids and of the surface energy of solids in terms of Owens-Wendt-Rabel-Kaelbe (OWRK) model incorporated in Young's equation. This yields the equation

$$
\frac{\sigma_{l}(1+\cos \theta)}{2 \sqrt{\sigma_{l}^{d}}}=\sqrt{\sigma_{s}^{p}} \sqrt{\frac{\sigma_{l}^{p}}{\sigma_{l}^{d}}}+\sqrt{\sigma_{s}^{d}},
$$

where $\theta$ is the contact angle. $\sigma_{l}$ is the surface energy of liquid and $\sigma_{s}^{p}, \sigma_{s}^{d}, \sigma_{l}^{p}$, and $\sigma_{l}^{d}$ the polar and dispersive components of the surface energies of liquid and solid. These parameters were evaluated 
by creating a regression line (shown in Figure S1 in the Supporting Information). The total surface energy of a solid was subsequently calculated as the sum of the polar and dispersion components

$$
\sigma_{s}=\sigma_{s}^{p}+\sigma_{s}^{d}
$$

AFM. AFM measurements of the thin-film morphology were performed on a Veeco Dimension 3100 AFM operated in tapping mode using BudgetSensors Tap300Al-G cantilevers. AFM images were analyzed using AFM image analysis software Gwyddion. ${ }^{29}$

GIXRD. GIXRD experiments were conducted at the UK CRG beamline XMaS (BM28) at the European Synchrotron Radiation Facility (ESRF). Samples were mounted onto a custom made circuit board allowing electrical connections to a ZIF-socket as illustrated in Fig. 1(a). This circuit board was placed inside a nylon/metal-printed sample chamber continuously flushed with helium in order to reduce absorption and air scattering. The X-ray energy was $10 \mathrm{keV}$ and the beam size was $50 \mu \mathrm{m} \times 350$ $\mu \mathrm{m}$ (height $\times$ width). The incidence angle was optimized for each sample to maximize the diffraction intensity and was kept between the critical angle of $\mathrm{NaT} 2$ and $\mathrm{SiO}_{2}\left(0.141^{\circ}-0.173^{\circ}\right)$. In this configuration, the X-ray footprint spans across the entire board for the employed incidence angles. The X-ray intensity images were recorded with an MAR165 CCD detector.

Two different detector arrangements were employed. In the first arrangement, the detector was directly in the forward direction and the sample-to-detector distance $338 \mathrm{~mm}$ covered the $q$ vector range horizontally up to $q_{x y}<1.95 \AA^{-1}$ and vertically up to $q_{z}<1.5 \AA^{-1}$, calibrated by a silver behenate standard. In the second arrangement, the detector was used in two different positions and two datasets were merged to extend the horizontal range to $q_{x y}<3.3 \AA^{-1}$. In the first position the right-hand edge of the detector seen from the beam was tilted $5.6^{\circ}$ and the upper edge $7^{\circ}$ towards the beam. In the second position, the corresponding tilts were $25.1^{\circ}$ and $7^{\circ}$. The sample-to-detector distance was also $338 \mathrm{~mm}$. 
The latter data showed two characteristic continuous rings at high angles corresponding to the powder scattering rings from the (111) and (200) reflections of the gold electrodes (see Figure S6 in the Supporting Information). Using these reflections as calibration measurements, sample-to-detector distances were derived for the angle set-up.

The raw pixel data were transformed into reciprocal $q$ space as described in Ref. ${ }^{30}$. This allows for each pixel to be mapped unto the effective detector angles (see Fig. 1 in Ref. ${ }^{30}$ ). As the samples were not rotated $\left(\phi_{h}=0^{\circ}\right)$, the pixels effective angular position corresponded to momentum transfer vectors in the horizontal geometry as

$$
\mathbf{H}=\left[\begin{array}{c}
X \\
\cos \omega_{h} Y+\sin \omega_{h} Z \\
\cos \omega_{h} Z+\sin \omega_{h} Y
\end{array}\right]
$$

where the sample tilt is $\omega_{h}=0^{\circ}$ for the images in question and where $(X, Y, Z)$ are momentum transfers in the laboratory frame. The peak positions were found by fitting cuts along the radial direction from the direct beam point and the lattice parameters were refined using weighted nonlinear regression. The refinement used previously reported cell dimensions for NaT2 single crystals as a starting point. ${ }^{22}$ The error estimate of the fitted parameters was found by the diagonal of the variancecovariance matrix of the fit and is given as \pm 1 standard deviation.

Figure 2 illustrates the contributing factors to intensity pattern broadening. The observed intensity pattern is smeared due to experimental imprecision $G(s)$ as

$$
I_{o b s}=I(s) * G(s)
$$

where $I(s)$ is ideal peak profile that is obtained under an ideal instrumental condition without instrumental broadening. 
For the vertical profile (crystal thickness), we considered intensity peaks close to the horizontal direction and one-pixel wide slices across the maxima as depicted in Fig. 2. Under these conditions, the experimental broadening is given by the beam height as

$$
G_{z}(s)=b(s),
$$

where $b(s)$ represents the broadening due to the limited beam. However, with the beam height $50 \mu \mathrm{m}$ of which slightly more than half impinges on the sample, this becomes negligible compared to the crystal size broadening.

For the horizontal profile (lateral crystal size), the slices were wider. Considering similar intensity maxima near the horizontal direction, the experimental broadening becomes a convolution of beam width $(b(s)=350 \mu \mathrm{m})$ and a sharply limited function $p(s)$ representing primary intensity in the NaT2 film along the finite width of the film as

$$
G_{x y}(s)=b(s) * p(s)
$$

Finally, the crystal size was estimated from the peak width analysis using the Scherrer equation

$$
\tau=\frac{5.655}{\Delta q},
$$

where $\tau$ is the mean crystal size, 5.655 is an approximate shape factor and $\Delta q$ the FWHM of $I(s)$.

The form of $p(s)$ depends on the incidence angle and the consistency of estimated crystal sizes was checked by varying the incidence angle. We estimate that our method is reliable for crystal sizes below $100 \mathrm{~nm}$ 


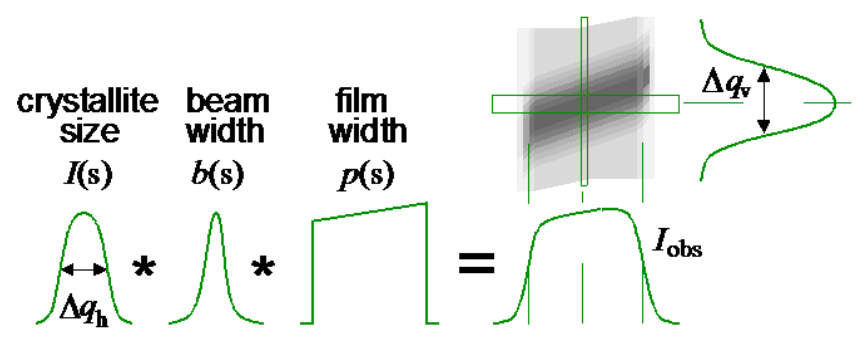

Figure 2. Schematics of intensity broadening due to the crystal size, beam width and film width.

The terms grains and crystals or crystallites (understood as small single crystals) are usually used interchangeably. In our discussions, however, we denote grains as 3-dimensional domains with vacant grain boundaries as observed by AFM. We denote crystallites as single crystals observed by X-rays (vide infra). Thus, grains can be polycrystalline and can contain several crystallites that consist of a single phase.

Electrical characterization. Electrical transport measurements were carried out during GIXRD measurements in operando by biasing the device with programmable voltage supplies Kepco BOP 100$10 \mathrm{MG}$ and Hewlett Packard E3620A one output for the gate and one for the drain biasing relative to common ground on source and recording the transfer characteristics with a Keithley 486 picoammeter.

A fixed drain-source voltage $V_{d s}$ was applied starting at $V_{d s}=0 \mathrm{~V}$, to the sample while the gate voltage $V_{g}$ was swept from $0 \mathrm{~V}$ to $-30 \mathrm{~V}$. A $90 \mathrm{~s}$ GIXRD measurement was then recorded and the gate voltage swept back to $0 \mathrm{~V}$. This procedure was repeated for $V_{d s}=0,-10,-20$ and $-30 \mathrm{~V}$. Additional measurements were done using a probe station set-up outside the beamline. The saturation mobility was calculated from ${ }^{3}$ as

$$
\mu_{s a t}=\frac{2 L}{C_{i} W}\left(\frac{\partial \sqrt{I_{d s}}}{\partial V_{g}}\right)^{2}
$$


where $C_{i}$ is the capacitance per unit area and $L$ and $W$ the channel length and width. This assumes that the contact resistance is negligible compared to the channel resistance, however, as the HOMO level of NaT2 $(5.43 \mathrm{eV})^{20}$ is relatively close to the work function of the gold electrodes $(5.1 \mathrm{eV})$, this is a reasonable assumption. The errors in measured mobilities were estimated from the uncertainties that result from fitting the measured data to Eq. (8). The threshold voltage $V_{t h}$ was found by the intercept between the square of the current $I_{d s}$ and voltage axis. 


\section{RESULTS AND DISCUSSION}

Surface morphology. We first consider the surface characteristics of the substrates studied by contact angle measurements. Table 2 compiles the surface energies for the employed OFET substrates with pristine $\mathrm{SiO}_{2}$ and with the OTS layer after anhydrous (A) or humid deposition (H). The data show clearly how OTS layer decreases the surface energy. Pristine $\mathrm{SiO}_{2}$ was interpreted as hydrophilic and the OTS treated substrates as hydrophobic in nature.

Table 2. Surface energy of prepared OFET substrates. ${ }^{a}$

\begin{tabular}{|c|c|c|c|c|c|c|}
\hline \multirow{2}{*}{$\begin{array}{c}\text { Gate } \\
\text { dielectric }\end{array}$} & \multicolumn{3}{|c|}{ Contact angle $\left({ }^{\circ}\right)$} & \multirow{2}{*}{$\begin{array}{c}\sigma_{s}^{p} \\
\left(\mathrm{~mJ} / \mathrm{m}^{2}\right)\end{array}$} & \multirow[t]{2}{*}{$\sigma_{s}^{d}$} & \multirow[t]{2}{*}{$\sigma_{s}$} \\
\hline & Water & $\begin{array}{l}\text { Diiodo- } \\
\text { methane }\end{array}$ & $\begin{array}{l}\text { Ethylene } \\
\text { glycol }\end{array}$ & & & \\
\hline $\mathrm{SiO}_{2}$ & 43 & 70 & 71 & 37 & 10 & 47 \\
\hline OTS A & 102 & 69 & 70 & 1 & 24 & 25 \\
\hline OTS H & 107 & 75 & 84. & 1 & 19 & 20 \\
\hline
\end{tabular}

We next focus on the surface morphologies of the substrates and NaT2. We observe significant differences between NaT2 layers deposited on pristine $\mathrm{SiO}_{2}$ or OTS-covered $\mathrm{SiO}_{2}$. As the largest differences are between NaT2 layers on $\mathrm{SiO}_{2}$ and NaT2 layers on anhydrously deposited OTS, we focus on these two cases. We begin our considerations from nominally 11 and $25 \mathrm{~nm}$ thick films and continue with $8 \mathrm{~nm}$ thick films. 

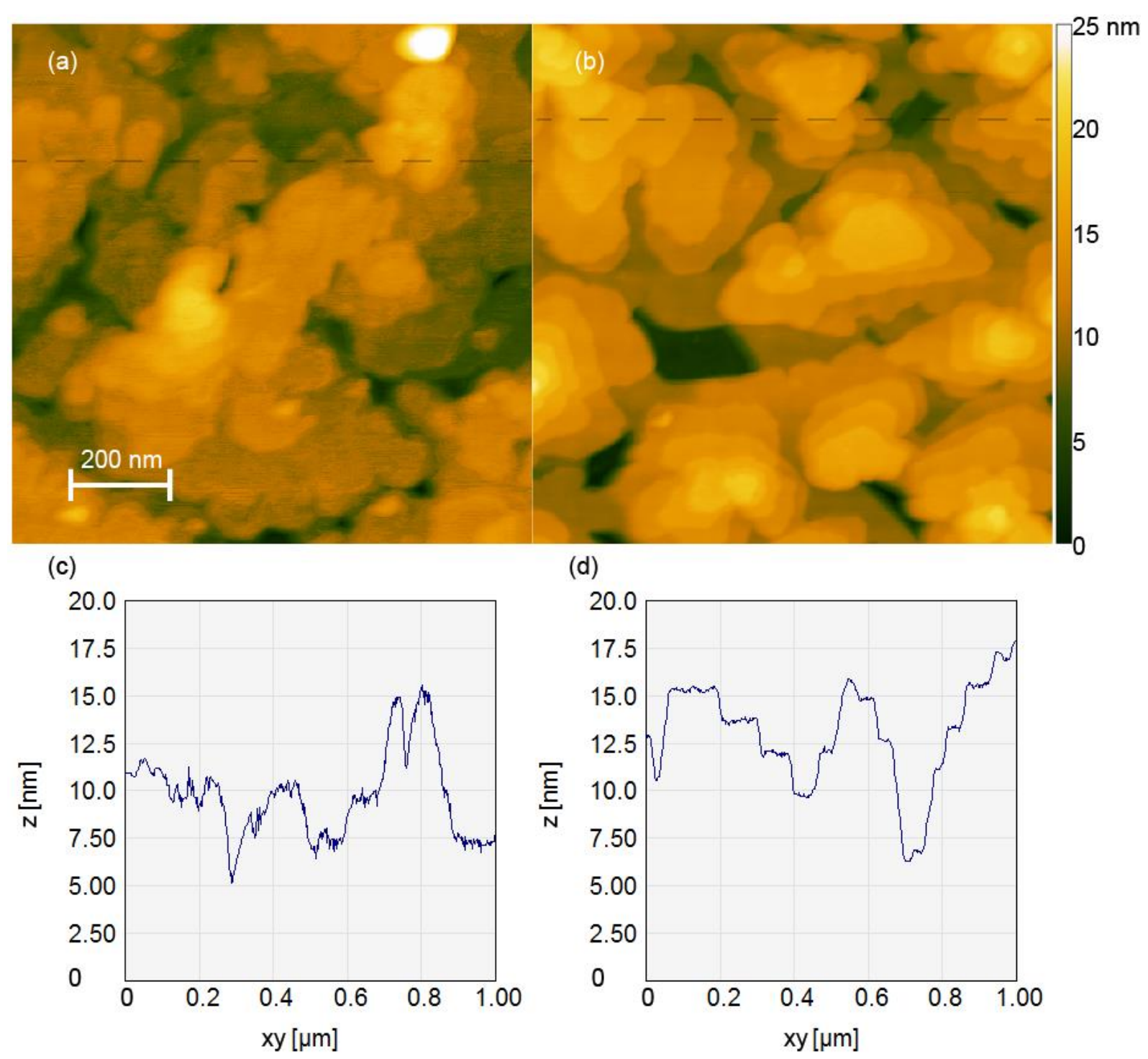

Figure 3. $1 \mu \mathrm{m} \times 1 \mu \mathrm{m}$ AFM scans of (a) N11 and (b) A11. Cross sections of (c) N11 and (d) A11 marked by dashed lines in panels $(a, b)$. 
Figure 3 shows characteristic AFM scans for nominally $11 \mathrm{~nm}$ thick NaT2 films on $\mathrm{SiO}_{2}$ (panel a) and on anhydrously deposited OTS (panel b) alongside characteristic cross sections (panels c and d). Corresponding 3D presentations are shown in the Supporting Information (Figure S2). All or nearly the entire surface is covered. In both cases NaT2 begins to form island-like formations, which are 100-300 $\mathrm{nm}$ wide and a few $\mathrm{nm}$ tall. These islands appear as featureless pyramids on $\mathrm{SiO}_{2}$. The situation is distinctively different on OTS where NaT2 grows as staggered pyramids where each step height corresponds precisely to one molecular layer $(2 \mathrm{~nm})$ or its multiple with the step distance of 50-100 $\mathrm{nm}$. This is an evidence for well-ordered 3-dimensional islands composed of distinct layers of NaT2 molecules. At the same time, the apparent grain size increases from approximately $100 \mathrm{~nm}$ on $\mathrm{SiO}_{2}$ to several hundreds of nanometers on OTS. This indicates that the nucleation density is significantly affected by the presence of the OTS layer leading to fewer and larger grains, which could indicate higher NaT2 diffusivity.

Figure 4 shows AFM scans for nominally $25 \mathrm{~nm}$ thick NaT2 films on $\mathrm{SiO}_{2}$ (panel a) and on anhydrously deposited OTS (panel b) alongside characteristic cross sections (panels c and d). Corresponding data over $10 \mu \mathrm{m} \times 10 \mu \mathrm{m}$ areas as well as the 3D presentation of Fig. 5(b) are shown in the Supporting Information (Figures S3 and S4). Again, the oligomer layers assemble as 10-20 nm tall pyramid grains (counted from the bottommost layer) that appear relatively smooth on $\mathrm{SiO}_{2}$ and wellstructured and staggered on anhydrously deposited OTS. The step height in the staggered pyramids corresponds to the individual molecular layer height $(2 \mathrm{~nm})$. These grains are clearly larger on OTS, which is better seen in $10 \mu \mathrm{m} \times 10 \mu \mathrm{m}$ scan (Fig. S3). The characteristic grain size is of the order of $100 \mathrm{~nm}$ for $\mathrm{N} 25$ and several hundreds of nanometers for A25. The fact that the regular, staggered pyramid architecture spans over larger macroscopic areas becomes obvious in Fig. S4. 


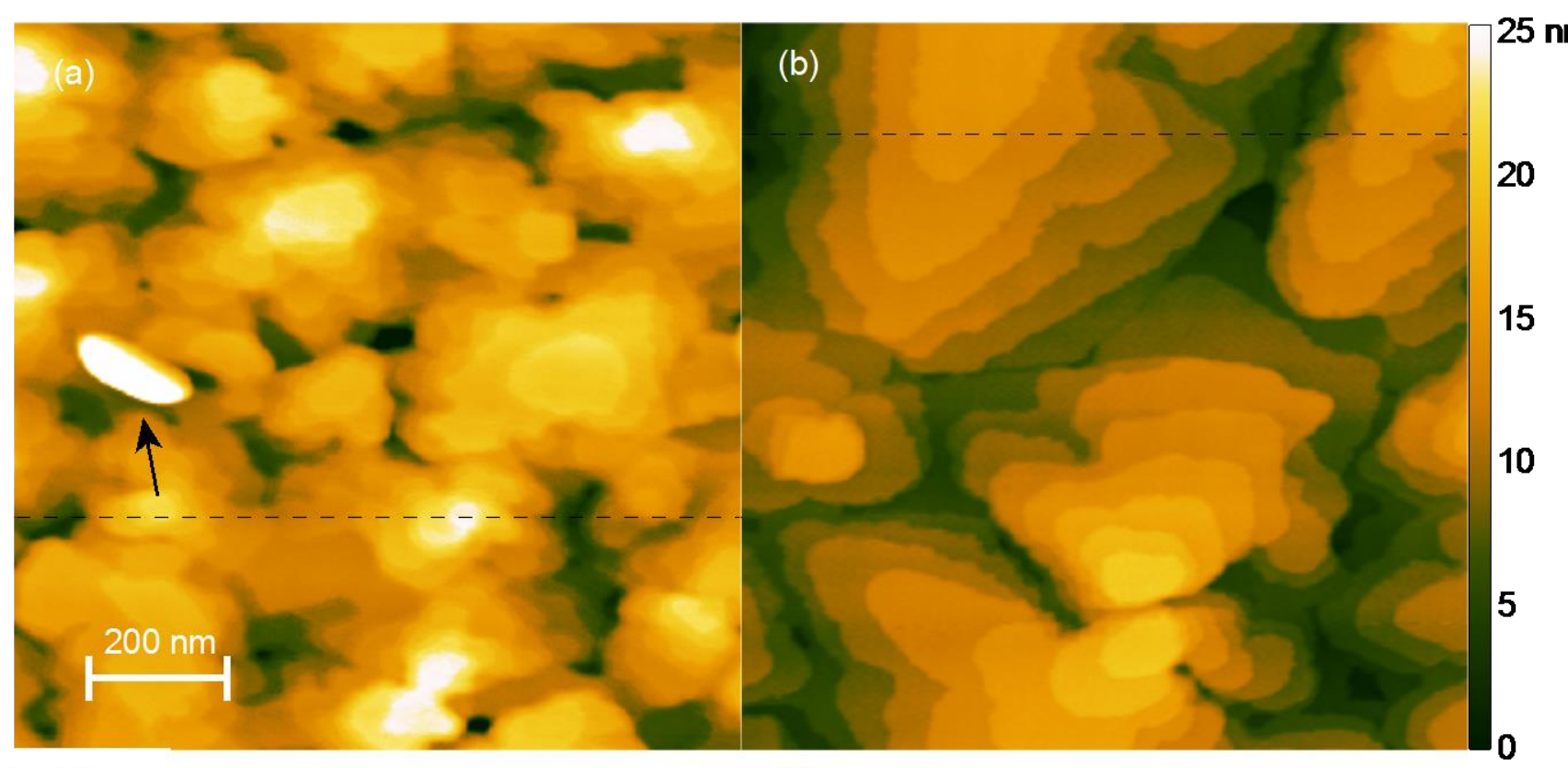

(c)

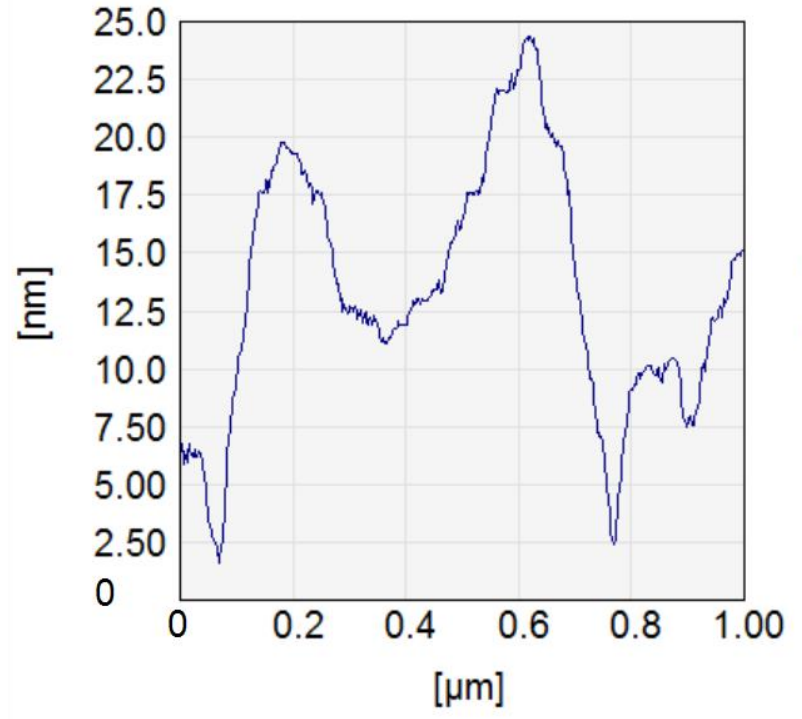

(d)

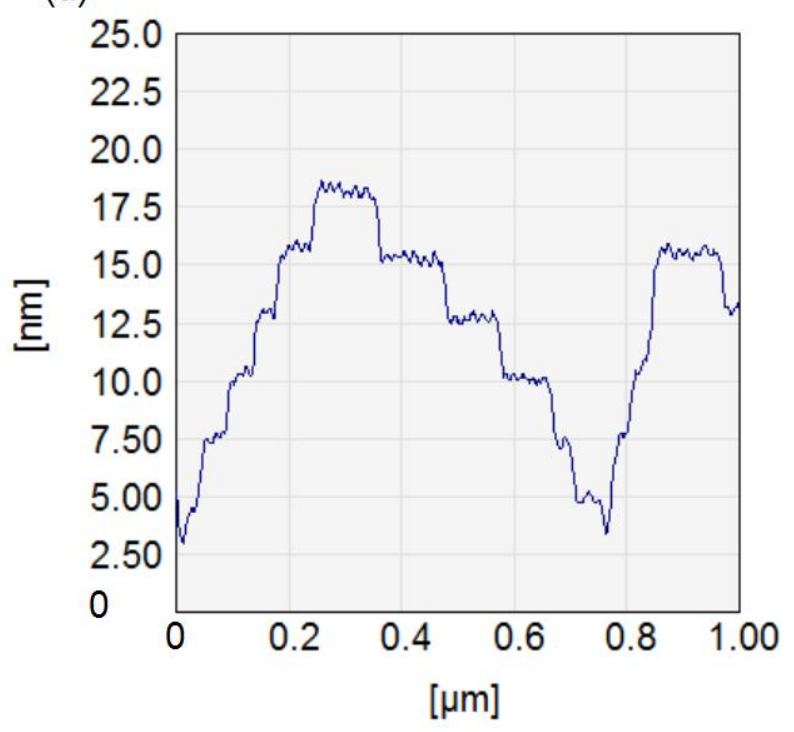

Figure 4. $1 \mu \mathrm{m} \times 1 \mu \mathrm{m}$ and AFM scans of (a) N25 and (b) A25. An arrow shows a spike-like “nanofiber". Cross sections of (c) N25 and (d) A25 marked by dashed lines in panels (a,b). 
Regardless of sample preparation, NaT2 layers manifest sporadically distributed 100-500 nm long $100 \mathrm{~nm}$ tall towering structures and these are most frequent for films on the OTS prepared in humid conditions. We tentatively identify them as the previously observed NaT2 "nanofibres", ${ }^{26}$ which correspond to molecules lying at a small angle to the surface, and which are known to form directly on the substrate surface on certain substrates such as muscovite mica under optimized growth conditions . One spike-like structure is seen in Fig. 4(a) and several in Fig. S3(b) and Fig. S5(b). Also shown in the Supporting Information are the corresponding data for $25 \mathrm{~nm}$ thick NaT2 on OTS deposited under humid conditions (Figure S5). The observed characteristics of H25 configuration are in between N25 and A25 containing both terraces and smoother areas.

Figure 5 shows characteristic AFM scans for nominally $8 \mathrm{~nm}$ thick $\mathrm{NaT} 2$ films on pristine $\mathrm{SiO}_{2}$ (panel a) and on anhydrously deposited OTS (panel b). Also shown are characteristic cross sections deduced from these scans (panels c and d). These thinner films, which represent the early stage growth, differ significantly from the above discussed thicker films. Both films contain flat 100-300 nm wide domains or grains that form continuous dewetting "percolating" networks over the device surface. These domains are approximately 1.5 times thicker $(10-14 \mathrm{~nm})$ than the nominal films thickness $(8 \mathrm{~nm})$ covering approximately two thirds of the surface while the rest of the surface remains seemingly empty. The overall thickness corresponds to 5-7 molecular layers each $2 \mathrm{~nm}$ thick. The total domain volume as estimated from the lowest surface level is close to the amount of substance evaporated for the given area. This suggests that the seemingly empty domains are actually empty and there is no NaT2 monolayer covering the entire surface. We are not able to say whether the first NaT2 layer could be partially embedded in the OTS layer. 

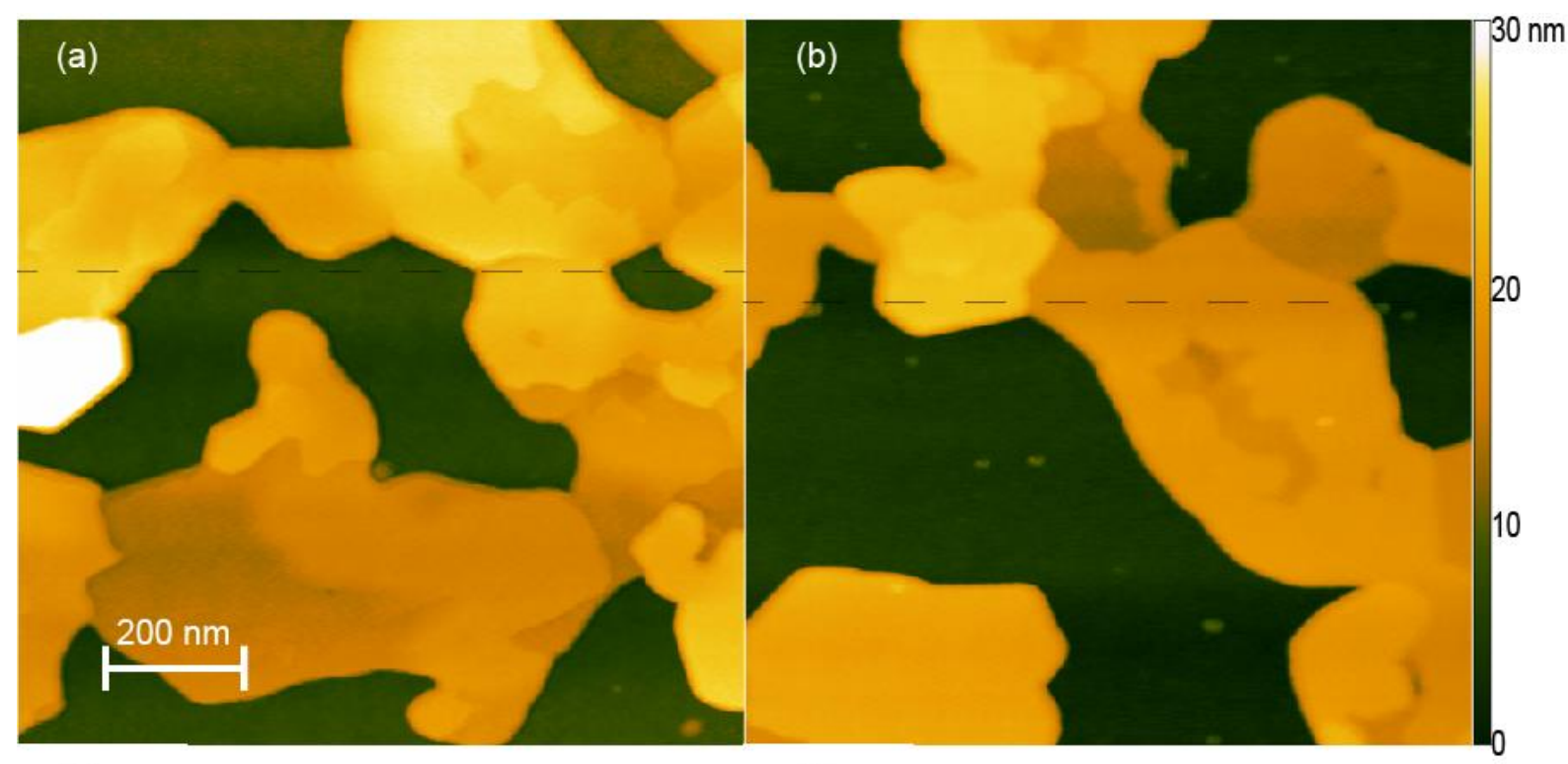

(c)

(d)
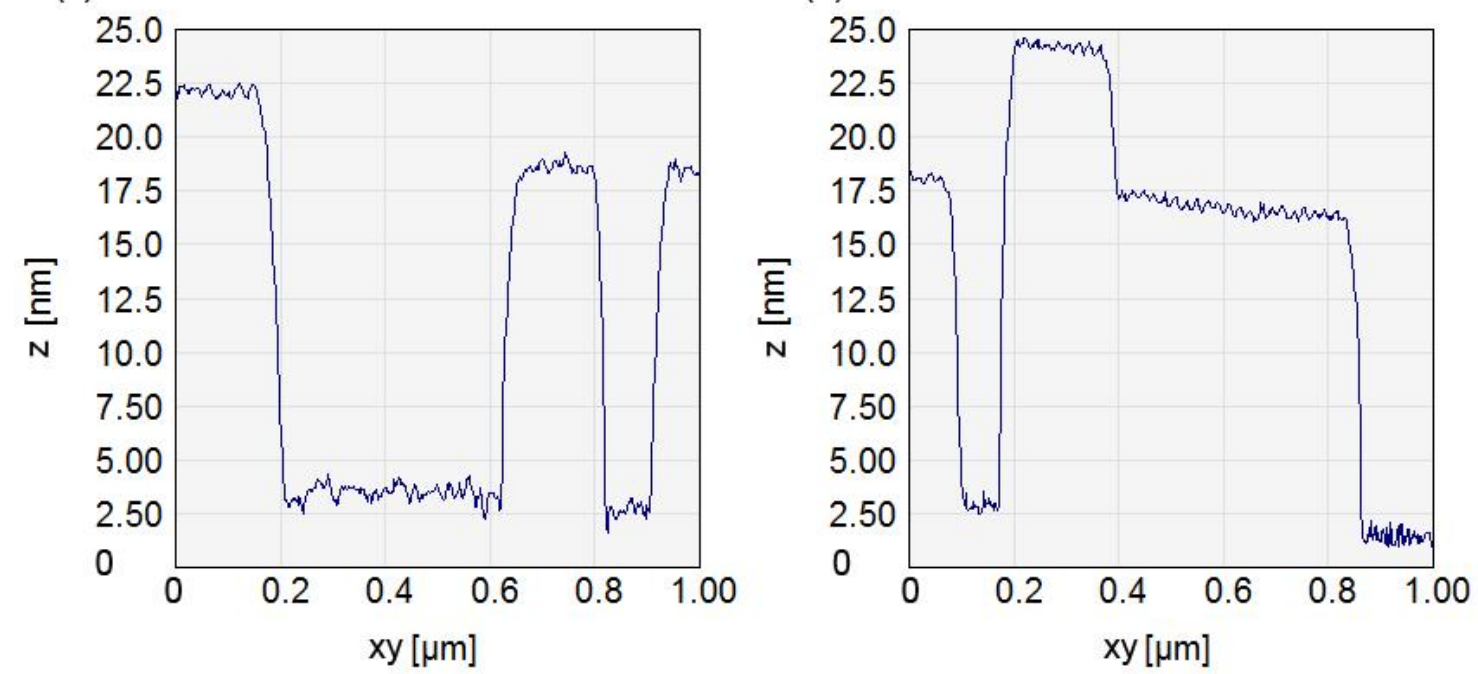

Figure 5. $1 \mu \mathrm{m} \times 1 \mu \mathrm{m}$ AFM scans of (a) N8 and (b) A8. Cross sections of (c) N8 and (d) A8 marked by dashed lines in panels $(a, b)$. 

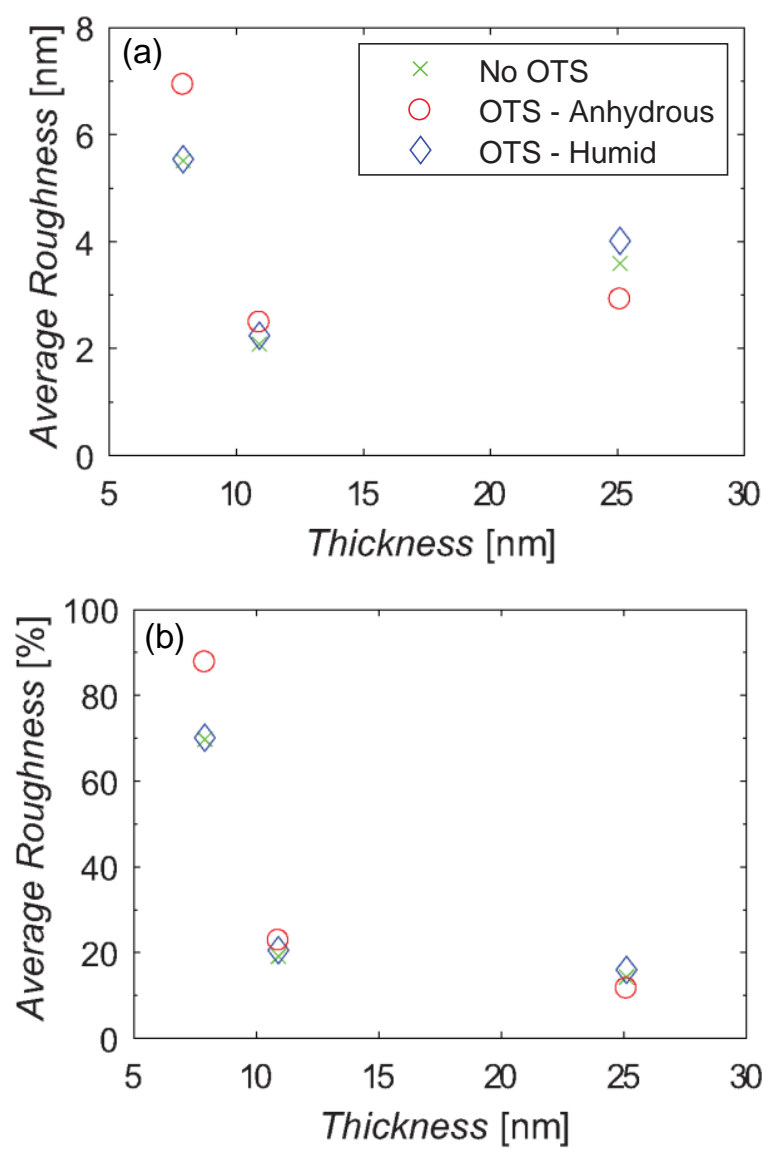

Figure 6. The RMS surface roughness of NaT2 layers on top of pristine $\mathrm{SiO}_{2}$ (green crosses) and on top of OTS from anhydrous deposition (red circles) or OTS from humid deposition (blue diamonds) in absolute (a) and relative units (observed roughness against the nominal thickness). (b). All data were measured over the area of $10 \mu \mathrm{m} \times 10 \mu \mathrm{m}$ (Fig. S3 and Figure S5).

Figure 6 plots the RMS surface roughness of the employed NaT2 films. The surface roughness of nominally $8 \mathrm{~nm}$ thick films is about $75-90 \%$ of the nominal film thickness. This agrees with the observation of thicker domains covering most but not the entire substrate surface. Thicker films are significantly smoother (11 nm - 20\% and $25 \mathrm{~nm}-10 \%)$. 
Crystalline structure and directional crystal size. We next focus on the crystalline structure and crystal size within the apparent film morphology. For this task we used GIXRD in two settings, which provided the overall data for the further analysis.

Figure 7 shows the GIXRD patterns for N25 at $q_{x y}<1.95 \AA^{-1}$. A high and a low angle diffraction pattern interlaced of the same sample covering a range of $q_{x y}<3.3 \AA^{-1}$ are shown in the Supporting Information (Figure S6). Corresponding image pairs were taken for all configurations and the lattice parameters and crystal sizes were deduced from data like these. Figure S7 plots the so obtained lattice parameters for all samples listed in Table 1. The unit cell level structure determined for NaT2 is monoclinic for all the employed OFETs with unit cell parameters $a=20.3 \AA, b=5.9 \AA, c=8.1 \AA$ and $\beta=96.9^{\circ}$. The cells are oriented forming a mosaic of crystallites where the $b$ - and $c$-axes on the plane and where the surface normal is defined by $a \cdot \sin \beta$.

Compared to the bulk structure, we do not observe characteristic substrate-induced phases, i.e., other polymorphs in OFETs. ${ }^{5}$ Interestingly, we do not observe significant differences in the unit cell parameters between $\mathrm{NaT} 2$ films on $\mathrm{SiO}_{2}$ and $\mathrm{NaT} 2$ films on OTS. The unit cell parameter $c$ corresponds to that in bulk while $a$ and $b$ are $1-2 \%$ smaller in films than in bulk. ${ }^{22}$ The unit cell volume tends to be smallest for the thinnest films, approaching that of bulk as the film thickness increases up to $25 \mathrm{~nm}$ (Figure 8). This trend is less clear for films on anhydrously deposited OTS which do not show a clear trend towards unit cell parameters of bulk. These effects may stem from differences in physical bonding between employed substrates and the first NaT2 layer, 

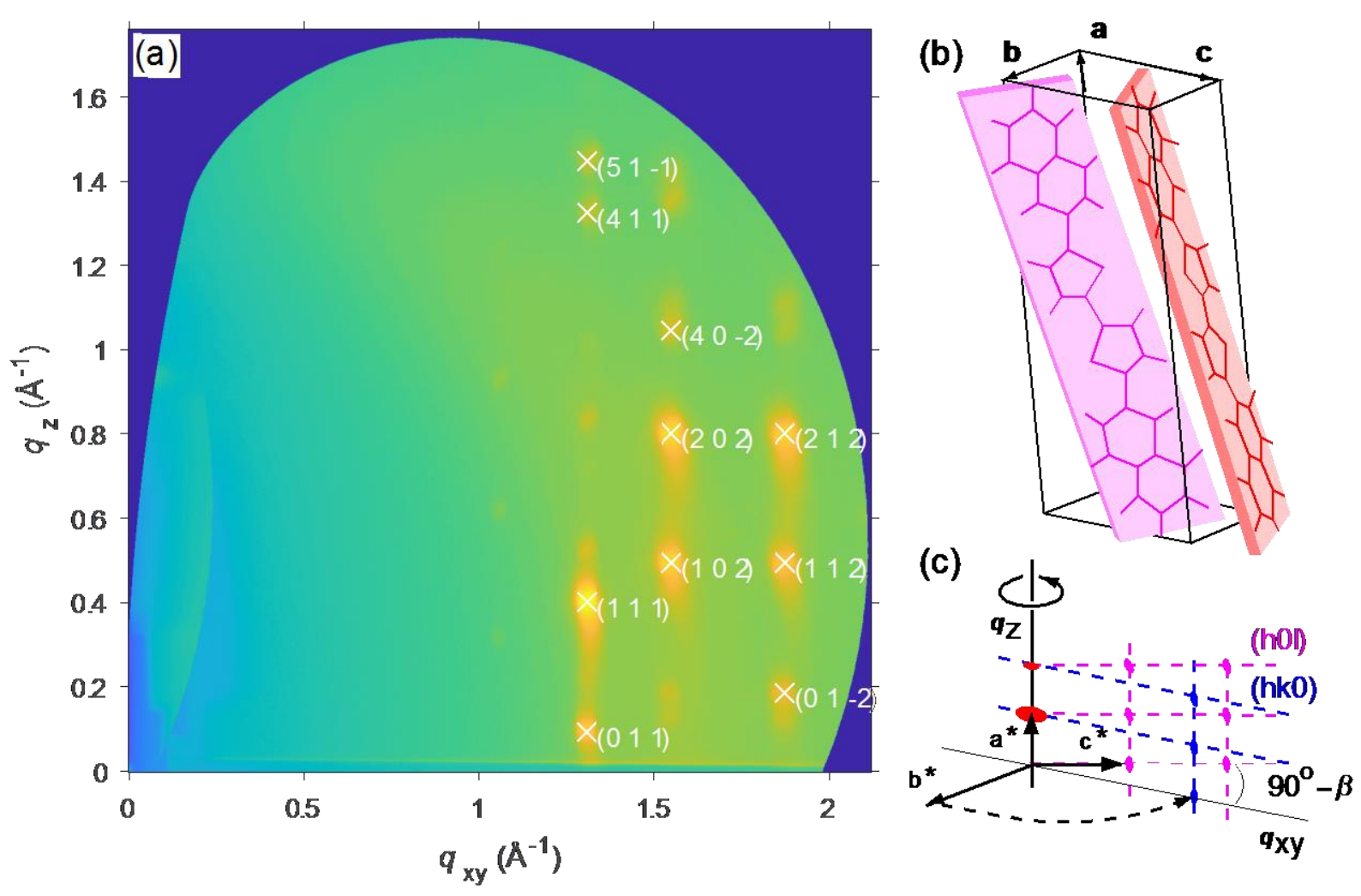

Figure 7. (a) GIXRD pattern of N25. White crosses mark the fitted peaks used for structure refinement. (b) Schematics of NaT2 unit cell and (c) experimental coordinates. 


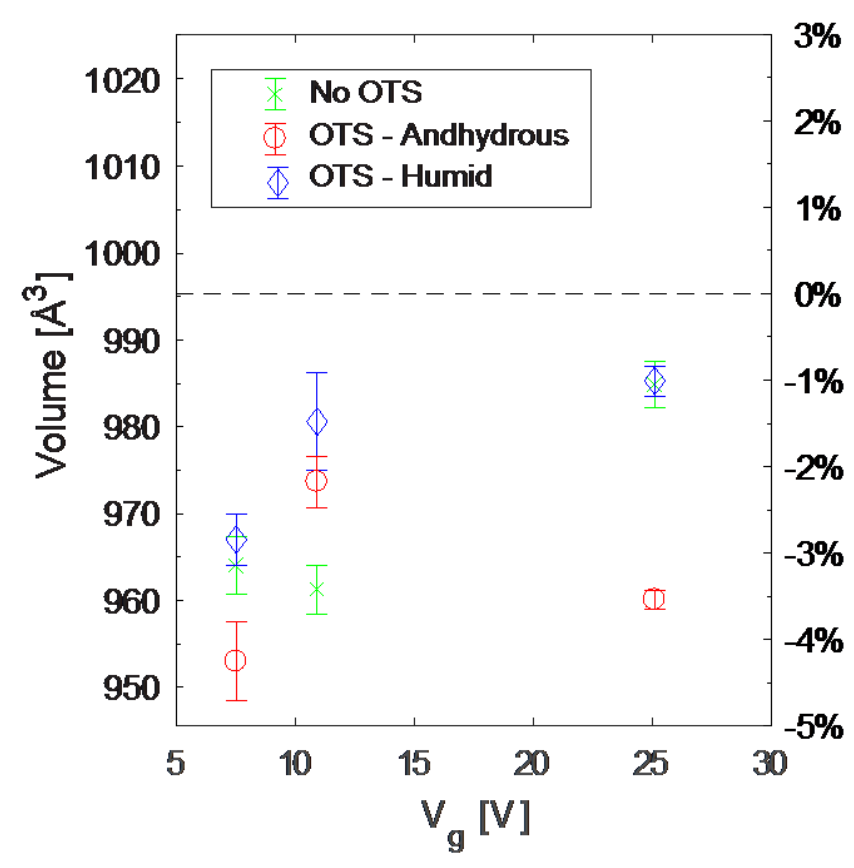

Figure 8 . NaT2 unit cell volume for the studied sample configurations. Green crosses refer to pristine $\mathrm{SiO}_{2}$ and red circles and blue diamonds, respectively, to OTS deposited under anhydrous or humid conditions. A horizontal line marks the unit cell volume in bulk reported by Tian et al. ${ }^{22}$

Table 3. Crystal sizes corresponding to various crystallographic planes compared to the film thickness estimated from the X-ray data.

\begin{tabular}{|c|c|c|c|c|c|}
\hline \multirow[t]{2}{*}{ Sample } & \multicolumn{4}{|c|}{ Crystal size in given directions } & \multirow{2}{*}{$\begin{array}{c}\text { Thickness } \\
{[\mathrm{nm}]}\end{array}$} \\
\hline & $\begin{array}{l}(010) \\
{[\mathrm{nm}]}\end{array}$ & $\begin{array}{l}\text { (h11) } \\
{[\mathrm{nm}]}\end{array}$ & $\begin{array}{l}(002) \\
{[\mathrm{nm}]}\end{array}$ & $\begin{array}{l}(012) \\
{[\mathrm{nm}]}\end{array}$ & \\
\hline $\mathrm{N} 8$ & 36 & 50 & 28 & 35 & $12.3 \pm 0.2$ \\
\hline A8 & $>100$ & 90 & 45 & 54 & $13.4 \pm 0.6$ \\
\hline $\mathrm{H} 8$ & 37 & 58 & 31 & 35 & $16.1 \pm 0.4$ \\
\hline N11 & 28 & 25 & 16 & 16 & $9.3 \pm 0.4$ \\
\hline A11 & 73 & 79 & 33 & 40 & $11.5 \pm 0.4$ \\
\hline H11 & 47 & 47 & 23 & 28 & $10.9 \pm 0.7$ \\
\hline N25 & 29 & 39 & 21 & 24 & $19.6 \pm 0.2$ \\
\hline A25 & $>100$ & $>100$ & 58 & 65 & $19.7 \pm 0.4$ \\
\hline $\mathrm{H} 25$ & 63 & 79 & 28 & 37 & $20.2 \pm 0.3$ \\
\hline
\end{tabular}


Table 3 compiles the determined crystal sizes for NaT2 along four crystallographic planes for all here employed OFETs. Also shown is the corresponding film thicknesses estimated form the X-ray data. While the unit cell structures remain similar regardless the sample configuration, OTS promotes larger NaT2 crystals, especially when the OTS is deposited under anhydrous conditions.

We can identify the following tendencies. First, considering every possible configuration, the crystal size is smallest for $\mathrm{NaT} 2$ films on pristine $\mathrm{SiO}_{2}$ and largest for NaT2 films on OTS prepared under anhydrous conditions. The crystal size for the NaT2 films on OTS prepared in humid conditions is in between these two cases. Second, crystal size is larger along the b-direction than along the c-direction. Third, the trends in the lateral crystal size follow those in the grain size. We note that while crystal sizes of A8 and N8 are very different, this difference is notes reflected in their morphology as shown by AFM images (Fig. 5). This implies that the morphological domains of N8 consist of several small crystals observed by X-rays. For the two thickest films the calculated film thicknesses agree with the nominal thicknesses determined by QCM measurements. Similarly, the crystal size along the surface normal corresponds to around $80-100 \%$ of the average film thickness for the 11 and $25 \mathrm{~nm}$ films, indicating a mosaic of single crystals. For the nominally $8 \mathrm{~nm}$ films the measured thickness maximum exceeds the nominal by around 50-100 \%. This is not an artefact but reflects the 10-14 nm tall domains covering roughly $2 / 3$ of the device surface. 
Electrical characterization and crystalline structure in operando. We will finally consider the electrical characteristics of the prepared OFETs - whether the morphology and crystal size influence their performance and whether the crystalline structure is influenced by the transistor operation. The IV-curves were measured for all the samples and the GIXRD images were recorded simultaneously. The saturation mobilities and the threshold voltages were estimated from the so obtained IV-curves. The $11 \mathrm{~nm}$ and $25 \mathrm{~nm}$ films conduct reliably but not all $8 \mathrm{~nm}$ thick samples (among several parallel samples) act as working OFETs. The reason for the latter is attributed to the lack of full coverage.

Figures 9 (a) plots the IV-curves of $11 \mathrm{~nm} \mathrm{NaT2}$ films on $\mathrm{SiO}_{2}$ and on anhydrously deposited OTS. Figure 9(b) compiles the saturation mobilities for $11 \mathrm{~nm}$ and $25 \mathrm{~nm}$ OFET configurations. IV-sweeps of the $8 \mathrm{~nm}$ film configurations shortly after deposition did not show consistent IV-curves and carrier transport in $8 \mathrm{~nm}$ film configurations were thus deemed unreliable. Considering all the studied samples with their parallel samples, mobilities are higher for $\mathrm{NaT} 2$ layers on $\mathrm{SiO}_{2}\left(2-3 \cdot 10^{-4} \mathrm{~cm}^{2} / \mathrm{Vs}\right)$ compared to NaT2 on OTS $\left(2 \cdot 10^{-5}-1 \cdot 10^{-4} \mathrm{~cm}^{2} / \mathrm{Vs}\right)$.

While we observe larger grains and at least 3 -fold increase in the lateral crystal size driven by OTS deposited under anhydrous conditions, the mobility levels are actually lower for OFETs with OTS. This is in contrast to the common assumption that larger grains lead to less grain boundary scattering and consequently higher mobility. We propose that the growth of larger grains is indicative or a more 3dimensional growth mode that results in voids and poorer intergrain connections in the first few molecular layers leading to a low intergrain mobility. In contrast, the thin-films on pristine $\mathrm{SiO}_{2} \mathrm{With}$ smaller grains might exhibit a more continuous morphology in the first few layers and consequently better intergrain mobility, leading to the observed differences in hole mobility. 
Indeed, there are several reports that some of the best performing thin-films consisted of small grains (see Ref. ${ }^{6}$ and references herein).
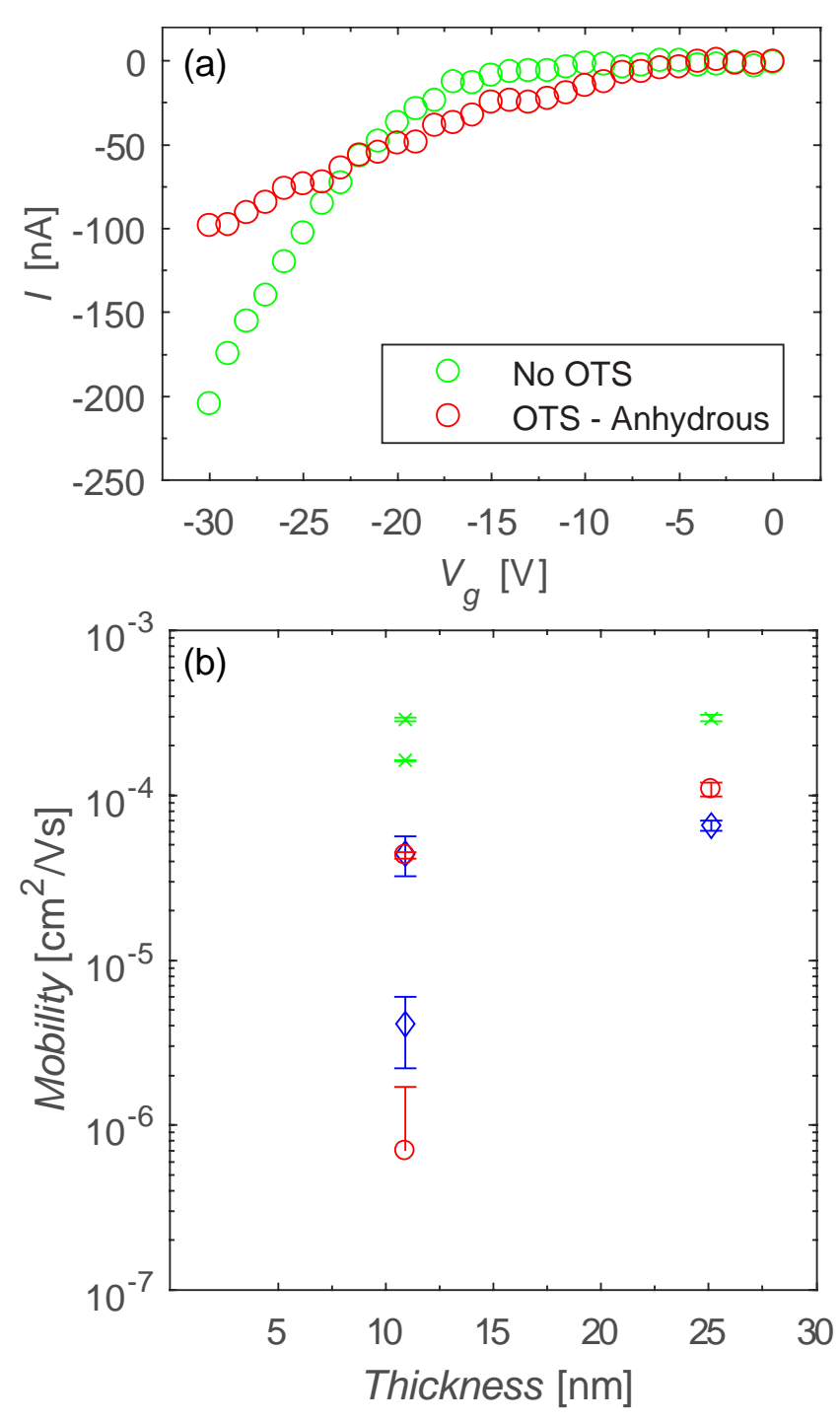

Figure 9. (a) I-V forward sweeps at $V_{d s}=-30 \mathrm{~V}$ for $\mathrm{N} 11$ and A11. (b) $\mu_{\text {sat }}$ for the nominally $11 \mathrm{~nm}$ and $25 \mathrm{~nm}$ film configurations. Green symbols refer to pristine $\mathrm{SiO}_{2}$ and red and blue symbols to OTS deposited under anhydrous or humid conditions. 

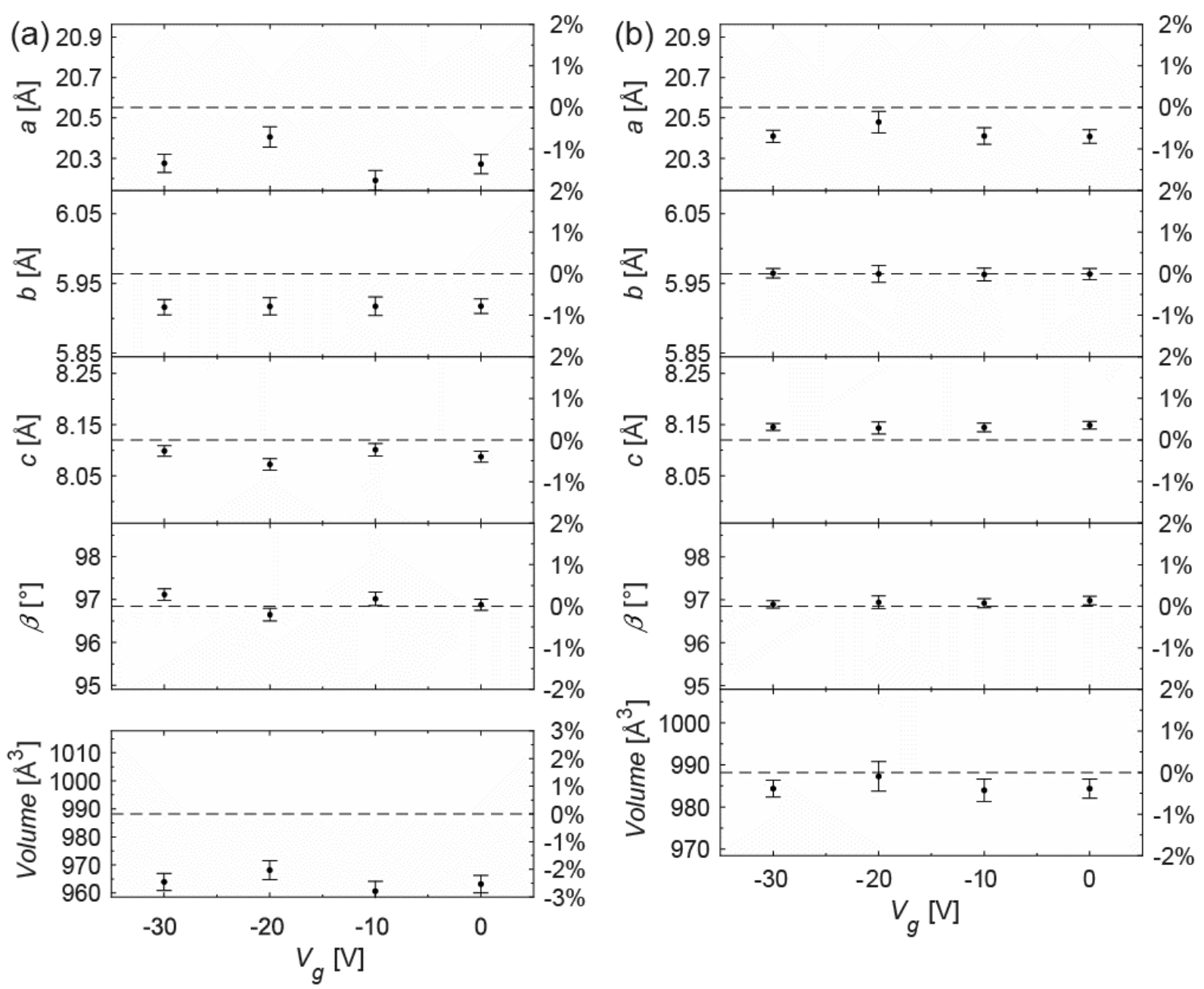

Figure 10. (a) Lattice parameters and unit cell volume as a function of $V_{g}$ for (a) N8 and (b) N25.

Figure 10 plots the lattice parameters against the employed gate voltage $V_{g}$ for the thinnest and thickest NaT2 OFETs. The NaT2 unit cell remains stable under an applied voltage with and without OTS for at least tens of minutes time Similar data are observed for other configurations (see Figure S8 in the Supporting Information). This agrees with our previous report ${ }^{25}$ where we observed $50 \mathrm{~nm}$ thick NaT2 films being stable and unit cell parameters staying constant under the same conditions for 10 hours of cycling. This can be discussed alongside the work of Liscio et al. ${ }^{31}$, who reported that pentacene will tilt towards the applied field in OFETs. 


\section{CONCLUSIONS}

This study concerns NaT2 and shows how it structure and morphology can be controlled by an OTS layer on the $\mathrm{SiO}_{2}$ gate dielectric in bottom-gate OFETs. This effect depends on the deposition conditions of OTS layer.

NaT2 deposited directly on the pristine $\mathrm{SiO}_{2}$ dielectric preferentially forms a mosaic of crystals where the film thickness matches the crystal size across the film. The lateral crystal size is approximately $30 \mathrm{~nm}$. NaT2 deposited on $\mathrm{OTS} / \mathrm{SiO}_{2}$ shows distinctive staggered pyramidal islands where the interlayer spacing corresponds to one unit cell with upright standing molecules. At the same time, lateral grain size observed by AFM increases from hundreds of nanometers up to micrometers.

The lateral crystal size determined by X-rays is larger $(100 \mathrm{~nm})$ if the OTS layer is deposited under anhydrous conditions and smaller $(30-70 \mathrm{~nm})$ if the layer is deposited under humid conditions. The unit cell parameters determined for OFET differ $1-2 \%$ from those in bulk. The unit cell volume is $1-4 \%$ smaller than that of bulk. Regardless of the OTS layer, the overall morphology depends on film thickness. While the 11 and $25 \mathrm{~nm}$ thick NaT2 films cover the whole OFET surface, nominally $8 \mathrm{~nm}$ thick films consist of submicron sized domains whose thickness exceeds the nominal thickness by $50 \%$ and covering two thirds of the FET area. Considering $11 \mathrm{~nm}$ and $25 \mathrm{~nm}$ thick films, the mobility levels tend to be higher for OFETs without OTS $\left(2-3 \cdot 10^{-4} \mathrm{~cm}^{2} / \mathrm{Vs}\right)$ compared to those with OTS $\left(2 \cdot 10^{-5}-1 \cdot 10^{-4} \mathrm{~cm}^{2} / \mathrm{Vs}\right)$. This is in contrast to the common assumption that larger grains lead to less grain boundary scattering and consequently higher mobility. This implies that the smaller grains in smoother films can be better interconnected and more tightly packed leading balancing improved 
intergrain transport for larger grains. An applied voltage does not influence the unit cell parameters when probed in operando.

Forthcoming studies should focus on the effect of deposition temperature, as this is known to influence the surface diffusion of the molecules, the grain size, and the resulting charge carrier mobility. ${ }^{22}$ They could also concern longer molecules such as NaTn with more thiophene rings and make a connection between surface morphology and crystallinity at the polymer-oligomer limit. ${ }^{32}$ Other material variations could involve alkane substituted oligothiophenes or similar, but asymmetric oligothiophenes where one naphthyl end-cap is replaced by aliphatic chains. ${ }^{33}$ It would be interesting to study the samples with complementary techniques such as cross-sectional transmission electron microscopy to characterize the thin-film morphology near the interface. Another possibility is to use napthalenes not as end-caps but as repeat units. ${ }^{34,35}$ Expanding studies from OFETs to photodetectors ${ }^{36}$ is yet some of the avenues worth pursuing.

\author{
ASSOCIATED CONTENT \\ Supporting Information \\ Regression lines according to Eq. 1 and additional AFM and GIXRD data. This material is available \\ free of charge via the Internet at http://pubs.acs.org.
}

\title{
AUTHOR INFORMATION
}

\section{Corresponding authors}

*E-mail andreas.lauritzen@,fysik.dtu.dk (A. E. L.)

*E-mail jkh@mci.sdu.dk (J. K-H.)

*E-mail: matti.knaapila@fysik.dtu.dk (M. K.)

\section{ORCID}


Andreas E. Lauritzen: 0000-0002-1726-7110

Mika Torkkeli: 0000-0001-8039-4000

Oier Bikondoa: 0000-0001-9004-9032

Jes Linnet: 0000-0002-4147-3694

Luciana Tavares: 0000-0002-1432-524X

Jakob Kjelstrup-Hansen: 0000-0003-4482-4979

Matti Knaapila: 0000-0002-4114-9798

\section{Notes}

The authors declare no competing financial interests

\section{ACKNOWLEDGMENTS}

We thank Arne Lützen and Andreas Osadnik of the University of Bonn for providing NaT2 and Kjeld Schaumburg of Roskilde University, Mathias Huss-Hansen of Technical University of Denmark and Michael J. Winokur of the University of Wisconsin-Madison for fruitful discussions. We acknowledge the EPSRC funded XMaS mid-range facility, DANSCATT, the SDU2020 program, the Danish Council for Independent Research (Grant ID 6111-00140) and MAX4ESSFUN of the European Regional Development Fund Interreg Öresund-Kattegat-Skagerrak (project DTU-038) for financial support.

\section{REFERENCES}

(1) Roncali, J.; Leriche, P.; Cravino, A. From one- to three-dimensional organic semiconductors: In search of the organic silicon? Adv. Mater. 2007, 19, 2045-2060. 
(2) Sirringhaus, H. Device physics of solution-processed organic field-effect transistors Adv. Mater. 2005, 17, 2411-2425.

(3) Zaumseil, J.; Sirringhaus, H. Electron and ambipolar transport in organic field-effect transistors Chem. Rev. 2007, 107, 1296-1323.

(4) Mannebach, E. M.; Spalenka, J. W.; Johnson, P. S.; Cai, Z.; Himpsel, F. J.; Evans, P. G. High hole mobility and thickness-dependent crystal structure in $\alpha, \omega$-dihexylsexithiophene singlemonolayer field-effect transistors Adv. Funct. Mater. 2012, 23, 554-564.

(5) Jones, A. O. F.; Chattopadhyay, B.; Geerts, Y. H.; Resel, R. Substrate-induced and thin-film phases: Polymorphism of organic materials on surfaces Adv. Funct. Mater. 2016, 26, 22332255.

(6) Virkar, A. A.; Mannsfeld, S.; Bao, Z.; Stingelin, N. Organic semiconductor growth and morphology considerations for organic thin-film transistors Adv. Mater. 2010, 22, 3857-3875.

(7) Verlaak, S.; Steudel, S.; Heremans, P.; Janssen, D.; Deleuze, M. S. Nucleation of organic semiconductors on inert substrates Phys. Rev. B 2003, 68, 195409.

(8) Di Carlo, A.; Piacenza, F.; Bolognesi, A.; Stadlober, B.; Maresch, H. Influence of grain sizes on the mobility of organic thin-film transistors. Appl. Phys. Lett. 2005, 86, 263501.

(9) Shin, E.-Y.; Cho, H. J.; Jung, S.; Yang, C.; Noh, Y.-Y. A high-k fluorinated p(vdf-trfe)-g-pmma gate dielectric for high-performance flexible field-effect transistors Adv. Funct. Mater. 2018, 28,1704780 .

(10) Roscioni, O. M.; Muccioli, L.; Mityashin, A.; Cornil, J.; Zannoni, C. Structural characterization of alkylsilane and fluoroalkylsilane self-assembled monolayers on sio2 by molecular dynamics simulations J. Phys. Chem. C 2016, 120, 14652-14662. 
(11) Kobyashi, S.; Nishikawa, T.; Takenobu, T.; Mori, S.; Shimoda, T.; Mitani, T.; Shimotani, H.; Yoshimoto, N.; Ogawa, S.; Iwasa, Y. Control of carrier density by self-assembled monolayers in organic field-effect transistors Nat. Mater. 2004, 3, 317-322.

(12) Chen, X.; Xu, Z.; Wu, K.; Zhang, S.; Li, H.; Meng, Y.; Wang, Z.; Li, L.; Ma, X. Facile peeling method as a post-remedy strategy for producing an ultrasmooth self-assembled monolayer for high-performance organic transistors Langmuir 2016, 32, 9492-9500.

(13) Lee, S.-M.; Lee, H. R.; Han, A.-R.; Lee, J.; Oh, J. H.; Yang, C. High-performance furancontaining conjugated polymer for environmentally benign solution processing ACS Appl. Mater. \& Interfaces 2017, 9, 15652-15661.

(14) Ito, Y.; Virkar, A. A.; Mannsfeld, S.; Oh, J. H.; Toney, M.; Locklin, J.; Bao, Z. Crystalline ultrasmooth self-assembled monolayers of alkylsilanes for organic field-effect transistors. $J$. Am. Chem. Soc. 2009, 131, 9396-9404.

(15) Virkar, A.; Mannsfeld, S.; Oh, J. H.; Toney, M. F.; Tan, Y. H.; Liu, G. Y.; Scott, J. C.; Miller, R.; Bao, Z. The role of ots density on pentacene and c60 nucleation, thin film growth, and transistor performance Adv. Funct. Mater. 2009, 19, 1962-1970.

(16) Shin, T. J.; Yang, H.; Ling, M.-m.; Locklin, J.; Yang, L.; Lee, B.; Roberts, M. E.; Mallik, A. B.; Bao, Z. Tunable thin-film crystalline structures and field-effect mobility of oligofluorenethiophene derivatives Chem. Mater. 2007, 19, 5882-5889.

(17) Walter, S. R.; Youn, J.; Emery, J. D.; Kewalramani, S.; Hennek, J. W.; Bedzyk, M. J.; Facchetti, A.; Marks, T. J.; Geiger, F. M. In-situ probe of gate dielectric-semiconductor interfacial order in organic transistors: Origin and control of large performance sensitivities $J$. Am. Chem. Soc. 2012, 134, 11726-11733. 
(18) Yang, S. Y.; Shin, K.; Park, C. E. The effect of gate-dielectric surface energy on pentacene morphology and organic field-effect transistor characteristics Adv. Funct. Mater. 2005, 15, 1806-1814.

(19) Osadnik, A.; Lützen, A. Synthesis of symmetrically functionalized oligo(het)arylenes containing phenylene, thiophene, benzthiophene, furan, benzofuran, pyridine, and/or pyrimidine groups Synthesis 2014, 46, 2976-2982.

(20) Rossi, R.; Bellina, F.; Lessi, M.; Manzini, C. Cross-coupling of heteroarenes by c-h functionalization: Recent progress towards direct arylation and heteroarylation reactions involving heteroarenes containing one heteroatom Adv. Synth. Catal. 2014, 356, 17-117.

(21) Meng, H.; Bao, Z.; Lovinger, A. J.; Wang, B.-C.; Mujsce, A. J. High field-effect mobility oligofluorene derivatives with high environmental stability J. Am. Chem. Soc. 2001, 123, 92149215.

(22) Tian, H.; Shi, J.; He, B.; Hu, N.; Dong, S.; Yan, D.; Zhang, J.; Geng, Y.; Wang, F. Naphtyl and thionaphtyl end-capped oligothiophenes as organic semiconductors: Effect of chain length and end-capping groups Adv. Funct. Mater. 2007, 17, 1940-1951.

(23) Yue, W.; Tian, H.; Hu, H.; Geng, Y.; Wang, F. Crystal packing motifs of oligothiophenes endcapped with $n$-containing aryls Cryst. Growth. Des. 2008, 8, 2352-2358.

(24) Liu, Y.; Di, C.-a.; Du, C.; Liu, Y.; Lu, K.; Qiu, W.; Yu, G. Synthesis, structures, and properties of fused thiophenes for organic field-effect transistors Chem. Eur. J. 2010, 16, 2231-2239.

(25) Huss-Hansen, M. K.; Lauritzen, A. E.; Bikondoa, O.; Torkkeli, M.; Tavares, L.; Knaapila, M.; Kjelstrup-Hansen, J. Structural stability of naphthyl end-capped oligothiophenes in organic field-effect transistors measured by grazing-incidence x-ray diffraction in operando Org. Elect. 2017, 49, 375-381. 
(26) Balzer, F.; Schiek, M.; Osadnik, A.; Wallmann, I.; Parisi, J.; Rubahn, H.-G.; Lützen, A. Subtrate steered crystallization of napthyl end-capped oligothiophenes into nanofibers: The influence of methoxy-functionalization Phys. Chem. Chem. Phys. 2014, 16, 5747-5754. Liu, X.; Tavares, L.; Osadnik, A.; Lausen, J. L.; Kongsted, J.; Lützen, A.; Rubahn, H.-G.; Kjelstrup-Hansen, J. Low-voltage organic phototransistors based on naphthyl end-capped oligothiophene nanofibers Org. Elect. 2014, 15, 1273-1281.

(28) Tavares, L.; Liu, Y.; Behn, D.; Siebels, J.; Kipp, T.; Mews, A.; Kjelstrup-Hansen, J. Laserinduced charge separation in organic nanofibers: A joint experimentaland theoretical investigation Org. Elect. 2018, 53, 20-25.

(29) Http://gwyddion.Net/faq.Php\#faq020.

(30) Schlepütz, C. M.; Mariager, S. O.; Pauli, S. A.; Feidenhans'1, R.; Willmott, P. R. Angle calculations for a (2+3)-type diffractometer: Focus on area detectors J. Appl. Cryst. 2011, 44, 73-83.

(31) Liscio, F.; Ferlauto, L.; Matta, M.; Pfattner, R.; Murgia, M.; Rovira, C.; Mas-Torrent, M.; Zerbetto, F.; Milita, S.; Biscarini, F. Changes of the molecular structure in organic thin film transistors during operation J. Phys. Chem. C 2015, 119, 15912-15918.

Knaapila, M.; Lyons, B. P.; Hase, T. P. A.; Pearson, C.; Petty, M. C.; Bouchenoire, L.; Thompson, P.; Serimaa, R.; Torkkeli, M.; Monkman, A. P. Influence of the molecular weight on the surface morphology of aligned, branched side chain polyfluorene Adv. Funct. Mater. $\mathbf{2 0 0 5}, 15,1517-1522$.

An, T. K.; Jang, J. H.; Kim, S.-O.; Jang, J.; Hwang, J.; Cha, H.; Noh, Y. R.; Yoon, S. B.; Yoon, Y. J.; Kim, L. H.; Chung, D. S.; Kwon, S.-K.; Kim, Y.-H.; Lee, S.-G.; Park, C. E. Synthesis and 
transistor properties of asymmetric oligothiophenes: Relationship between molecular structure and device performance Chem. Eur. J. 2013, 19, 14052-14060.

Mišicák, R.; Novota, M.; Weis, M.; Cigáň, M.; Šiffalovič, P.; Nádaždy, P.; Kožíšek, J.;

Kožíšková, J.; Pavúk, M.; Putala, M. Effect of alkyl side chains on properties and organic transistor performance of 2,6-bis(2,2'-bithiophen-5-yl)naphthalene Synth. Met. 2017, 233, 1-14.

Tian, H.; Chen, Y.; Li, W.; Yan, D.; Geng, Y.; Wang, F. Synthesis, characterization and semiconducting properties of oligo(2,6-naphthalene)s Org. Elect. 2014, 15, 1088-1095.

Linnet, J.; Walther, A. R.; Albrektsen, O.; Tavares, L.; Eriksen, R. L.; Jensen, P. B. W.; Osandnik, A.; Hassing, S.; Lützen, A.; Kjelstrup-Hansen, J. Enhanced photoresponsivity in organic field effect transistors by silver nanoparticles Org. Elect. 2017, 46, 270-275.

\section{For Table of Contents use only}

"Structural evaluation of 5,5'-bis(naphth-2-yl)-2,2'-bithiophene in organic field-effect transistors with octadecyltrichlorosilane coated $\mathrm{SiO}_{2}$ gate dielectric"

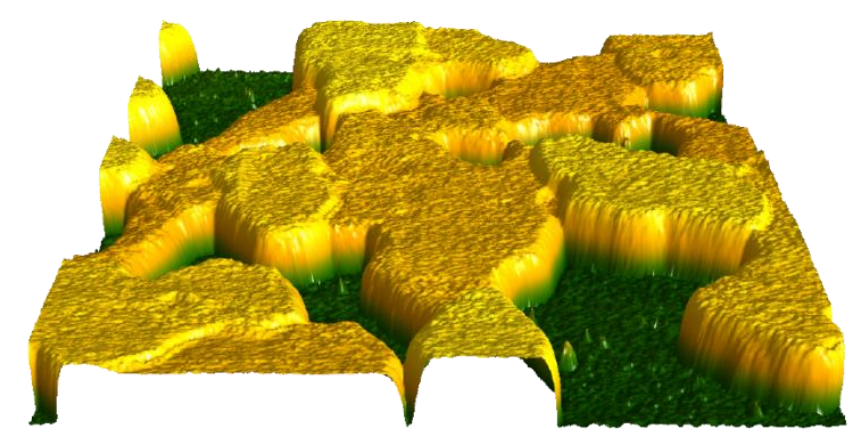

by Andreas E. Lauritzen, Mika Torkkeli, Oier Bikondoa, Jes Linnet, Luciana Tavares, Jakob KjelstrupHansen and Matti Knaapila 